\title{
MYTHICAL SYSTEMS: MATHEMATIC AND LOGICAL THEORY
}

\author{
J. Nescolarde-Selva and J.L. Usó-Doménech and M. Lloret-Climent \\ Department of Applied Mathematics. University of Alicante. Alicante. Spain.
}

\begin{abstract}
The process of elaboration of the symbolic universe leads to exciting insights regarding the search for human emotional security. The symbols end up as explanatory axes of universal reality and on them were constructed myths that form a superstructure for belief systems. Human society is a multilevel system with a material structure (society), an ideological superstructure (belief systems, values, etc) and a supersuperstructure with two parts: mythical (origin and justification) and utopic (final goal). All mythical belief systems have a numinous-religious nature.
\end{abstract}

Keywords: Belief system, denotation, modal logic, myth, mythical dimension, sign, significance, superstructure

\section{INTRODUCTION: WHAT ARE MYTHS?}

In its true meaning, the myth is a sacred narrative andtherefore symbolic. The storytelling of myth is not just story-telling it functioned as sacred history. It is Symbolic, and it links referent with significance, especially sacred significance. The potent social function of myth facilitates its use in interpreting literature, speech and revealed religion. Thus, for example, the myth of Oedipus is interpreted as literary tragedy from the pen of Sophocles. No doubt Sophocles tragedy has its origin in myth as a symbolic oral narration of family psychodynamies to explain family relationships. Myths are symbolic tales of the distant past (often from primordial times) that concern cosmogony and cosmology (the origin and nature of the universe), that may be connected to belief systems or rituals, and may serve to direct social action and values. Myths that can be described as "cosmogonic," or "origin" myths, function to provide order or cosmology, based on "cosmic" from the Greek kosmos meaning order (Leeming 1990; Bascom, 1965). Cosmology's concern with the order of the universe finds narrative, symbolic expression in myths, which often helps establish important values or aspects of a culture's worldview. For many people, myths remain a value-laden discourse that explains much about human nature.

Let us note that every myth usually involves rituals that are somewhat bodily and/or "Monumental" (spatial and temporal) inscriptions or, most often, a combination of both. It is therefore quite possible that the combinational logic of myth expresses in narrative important features a society's experience. Put another way, it seems possible to decode the combinatorial logic behind myth-making. This logic constrains the "interpretation" of the relationships (harmonic / disharmonic) between the members of a group of people and their environment.

Myths also:

Myths can provide continuity and stability to a culture. The stories themselves promote values, history and literature. Through them we connect with each other, to our ancestors, to the natural world around us and with other cultures. 
When myths speak of the activities and attitudes of deities, the moral tone implies society's expectations of our own behaviors and norms. In myths, we see archetypal situations and some of the options that can be selected.

Myths also justify the activities of a culture. Through the respect shown to authority and the characters in them, myths establish social customs, cultural rituals, religious principles, laws, social structures, power hierarchies, territorial claims, arts and crafts, festivals, and technical expertise for hunting and war.

The myths give meaning to life. We transcend our common life in a world in which deities interact with humans, and we believe that our daily actions are part of divine schemes. In our daily life our problems are more bearable because we can interpret the difficulties as having meaning. It is possible to place human suffering in a larger context, rather than feeling battered by random causes. And when we read that a particular deity experienced something we're supporting - maybe a fight against the "forces of evil" - we can feel that our own struggle could have a cosmic significance being similar to archetypal struggles, though on a smaller scale.

Myths reveal our fate after death, and the reasons for crises or miracles, yet retain and even encourage an aura of mystery. Myths also satisfy our need to understand the natural world. This purpose of mythology was especially important before the advent of modern science, in which the Big Bang theory replaces creation myths, and the theory of evolution replaces myths concerning the origin of the humanity. Finally, myths offer role models that children learn about in comics and cartoons and often imitate (Gash \& Domínguez Rodríguez, 2009).

It is difficult, if not impossible, to say exactly what the myths meant to those for whom they were central to their culture. Certainly, in so far as mythical thinking is an aspect of the human spirit showing a "wild" untamed face with its non-critical assembly of facts. In man there is always mythical or witd thought, although we may distrust it or try to exclude it. However, as Schweder (1977) had pointed out the human mind is inclined to seek connections between events where there is no good evidence for a causal connection. What we get from myth thus depends on our own world vision and our readiness to accept mythic connections. The evidence on risk assessment strongly supports this view of cognition (Evans, 2012).

The story-telling culture is clearly not always about a mythic narrative. Rather describing and explaining myths involves examining the recursive systems involved in people's understanding of their culture, in fact, the "myth story" could be illustrated with the symbol of the interlocking circles:

1) Circle of Orality: The word can be considered as power. In this case naming functions both to capture and give life. The word in this way can become a (re)creative game that allows substantial cultural insights. In Hebrew adama means land, from this comes the word to define man: Adam. In the Hebrew culture a man without land is not a human being. If one considers the suffix dam (blood), it has the same root as Adom (red), Dam, Adama, Adam, Adom. If these concepts are what define existence, then there is no choice but to shed blood for the sake of the land that defined Adam as a human being. Again, Rome (ROMA) if we write it backwards (AMOR) is a symbol of Love (AMOR). And a final example, myth, from the Greek mythos, means word-narrative, and as such, can 
be contrasted with logos, word-speech, remembering that the written word loses the life it has in oral expression.

2) Circle of Origin: The mythical story explains Time before the time we know, or the Event before the events. So, this story, in its essential aspect and therefore "sacred" aspect, tends to meet the Time before time, the Model before copies, and to repeat what worked (as well) in the Origin. The present then imitates and repeats the Great Past. Similarly, the future will be the Grand Past finally recovered, reinterpreted. It will be well appointed and well told. We have said "origin", but it would be better to speak of "the origins" because "at the origin" not everything is concomitant. The origin of the gods usually precedes that of men, and is preceded in turn by the world. Similarly, the origin of women tends to follow that of man. In other words, in every culture there is a myth about origin because it recounts a primary event that we cannot locate in ordinary time.

3) Operating Circle: Finally, the mythic narrative is operational, it is necessary that the storyteller and hearers act as though this is the case. One is reminded of the serious nature of genuine Irish music played in a pub. It is considered very bad manners to talk during such a performance. Myth telling is not just any storyteller or any public, nor does this "narrative" occur in any place or time. On the contrary, the myth requires a ritual to create a dual unit between teller and audience. Community and myths are intertwined to the point where whoever is excluded from hearing the myth is also excluded from the community. Conversely, whoever is not a member of the community, to them myth does not say anything. In other words, when story uses the word as power and sacred play, and recounts the occurrence of what came to its fullness for the first time in Primordial Time, and the story joins with the ritual to imitate its efficient operation, all in a symbolic language, then that narration is a mythic narrative. Regarding what seems enigmatic and unbelievable, myth tells about the incredible in the immanent present. Just as with the "miracle" of the creation of the world, all other particular miracles seems small. In a similar way all unbelievable particular myths are not "as" unbelievable as the creation myth. It is as if the incredible fact of existence could only be a correspondingly amazing story. The more fabulous the story, the more likely it is to be adjusted to reality. Moreover, the word, being invisible is the only mechanism capable of capturing the invisible in the future. Myth does not explain in the proper sense, but it narrates, imitates and represents through rituals It tells a symbolic story about the bond between members of a community that, thanks to the myth-ritual, believe in its integrity and this includes narrating its sacred origin. For modern man, believing and understanding maintain a strained feedback relationship: one must understand to believe, but one believes in understanding. In a way in myth, belief and understanding are the same. Such fusion is possible thanks to the plasticity, openness, and manageability of symbols that always says something more than word-images.

From classical times positions on myths have been well defined: 
1) Myths are pure fable. In the best case, myths are a free, bland and venial game. At worst, they are dangerous and harmful because of their possible consequences. This is the position of Xenophanes of Colophon ${ }^{1}$.

2) Myths have some truth. Myths talk about some meaningful feature of the human condition. In other words, by using allegorical procedures, they take a different perspective on something that could be described directly. They say "otherwise" what one could say "real". Sometimes the meanings are hidden but with careful examination one can find the meaning. Myths mask a reality-truth. Who lifts the veil can name the truth and reveal the reality since this then dispenses with the myth and one sees it only as an allegorical ornament, a literary procedure, or a means to imagine what it has to abstract the conceptual "reality-truth". That was Euhemerus' position ${ }^{2}$.

3) Myths speak of a different truth from that understood in conceptual discourse. Myths speak of a way to grasp the absolute other. Myths often tell of the "origin" or "final" or "permanent cause". They speak to that "absolutely other" that poetry, art or philosophy try to say in their own way. Myths tell of the ineffable, the indescribable, like something that has appeared for the "first time", and is still there, that "quite another" there is in all things.

Confronting these three attitudes, we realize in fact that the first two have something in common. Indeed, to put myth on the side of fable, it definitely disqualifies any pretense of truth, however small the claim may be. But on the other hand to recognize myth as containing some truth, it remains important not reject the myth, useless after being thorough analysis. When we talk about something, we always have reasons to ask the question: What are we talking about? But once we recognize what we mean "really",

\footnotetext{
${ }^{1}$ Xenophanes was a phusikoi in the Milesian tradition He was born in Colophon, not far from Miletus, around the year 570 B.C. After Colophon fell to Medes, Xenophanes left the city, becoming a wandering poet and philosopher. It is not known exactly where he traveled, but it seems likely that he visited southern Italy at some point, since he is clearly familiar with the Pythagorean doctrine of the transmigration of souls. He apparently wrote on purely poetic matters, even authoring a work on how to prepare for a drinking party (symposium), but he was also very interested in natural philosophy and religion. He was adamant in rejecting the Olympian account of the gods, insisting instead that there is only one, non-anthropomorphic god who is unmoving, but all-seeing, all-hearing, and all thinking, and who controls the universe with his thought. It seems plausible that his theological views were in a sense similar to the theological views of the Milesian philosophers, who all seemed to attribute some sort of divinity to their physis.
}

2 Euhemerus, 300 B.C., Cyrenaic philosopher, b. Sicily. He is famous for a theory of mythology embodied in his philosophical romance, Sacred History, a work of which only fragments remain. Euhemerus' theory, called after him euhemerism, was that the gods originated from the elaboration of traditions of distinguished historical persons. His theory was consistent with the attempts of his period to explain religious beliefs in terms of naturalism. "As regards the gods, then, men of ancient times have handed down to later generations two different conceptions: Certain of the gods, they say, are eternal and imperishable, such as the sun and the moon and the other stars of the heavens, and the winds as well and whatever else possesses a nature similar to theirs; for each of these the genesis and duration are from everlasting to everlasting. But the other gods, we are told, were terrestrial beings who attained to immortal honor and fame because of their benefactions to mankind, such as Herakles, Dionysus, Aristaeus, and the others who were like them..." 
then myth is as futile as an insufficient explanation compared to a better explanation, as useless as a partial truth compared to a proved truth.

Only the third approach clearly expressed the value and dynamics of the myth, whether we believe in an "all other" transcendent, invisible forever true, as a truth revealed. In myth it becomes visible and we are able to speak. By demythologizing we do not find the truth, not even if we discover, in the best case, the knowledge, but we tend to "guess" the truth of the "absolutely other", or the truth that goes along with the thing.

We will briefly examine Plato's treatment of myths. On the one hand he uses myth, narrated in his own way. Sometimes he even uses myths as educational or socially useful "lies". That gives an idea of his ambivalence, however when he resorts to myth because it is the only way to think about topics that seem impossible or too difficult for a number of onlookers.And shall we just carelessly allow children to hear any casual tales which may be devised by casual persons, and to receive into their minds ideas for the most

part the very opposite of those which we should wish them to have when they are grown up? (Republic, http://www.idph.net, page 230-231. To raise an obvious question, Plato criticizes mother and nurses, most of whose fables to be rejected. After criticizing Hesiod, Homer and other poets who composed fables that told lies (Platón, 1989).

Cohen's (1869) description of myths also brings up the idea of falsehood:

Cosmogonic Narratives, connected with the foundation or origin of the universe. These narratives have a sacred nature often connected with some ritual. They have an educational role and reflect the social order or the values within a culture. They are representative of a particular epistemology or a way of understanding nature and organizing thought. Mythic narratives often involve Heroic characters (possibly protohumans, super humans, or gods) and may be counter-factual in featuring actors and actions.

For Tylor (1871), myth provides knowledge of the physical world as an end in itself. Myth and science are identical in one function. Both serve to account for all events in the physical world. Yet they are not redundant accounts, the two are incompatible. It is not simply that myth is no longer needed once science arises, myth is no longer possible. Mythic explanations of human phenomena like customs and institutions may be fantastic and in that sense unscientific. Frazer (1922) argues that the knowledge that myth provides is a means of understanding the physical world. Myth is false because it is tied to magic, which stems from the failure to make basic logical distinctions. As illustrated by voodoo, magic fails to distinguish between symbol and the symbolized. Magic puts myth into practice in the form of ritual, which is an attempt to gain control over the physical world, especially over crops. Typically, the king plays the role of the key god of the pantheon, that of vegetation, and acts out the key part of the myth, or biography, of the god: his death and rebirth.

Anthropologist and folklorist Paul Radin (1950) considers myth distinctive because of its function and implications that are determined by certain individual society members. The myth-makers then explain symbolically how to live, as Radin (1950: 370) notes: "A myth is always explanatory. The explanatory theme often is so completely dominant that everything else becomes subordinated to it ..." Myths serve to explain and encourage a worldview and good actions within society. Many other theorists of myth concur that it has this functional dimension. 
Myths differ from other narratives commonly collected as folk tales and legends. Many of the great social theorists of the 19th century and early 20th century, used myths as evidence of universal truths. Lévi-Strauss (1974) used deductive methods to analyze myths. Recently, William Hansen (1998), argued that the sacred element of myth is a recent addition to the definition of myth. But in his studies of ancient Greek myths, Hansen (1998) points out that not all myths have a sacred element. They were not necessarily related to religious beliefs, but were often secular stories. While some myths do not have to have a sacred element, myths in general do seem to share an educational role in providing a worldview. Myths have been defined as true stories of ancient times. Malinowski (1992) added that they must be sacred, and discussed how they served society as a charter for action. Malinowski argued that myth is essential for the perpetuation and maintenance of normal social processes. Bidney (1950) following Malinowski, contends that every society clearly distinguishes between myth, fact (or what is taken for fact) and fiction (folk-tale). In this sense, then, no society is different from any other. Insofar as myth is the issue, the difference between one society and another is in the kind of myth developed. Pre-critical societies develop myths concerning magic and their culture-heroes; critical but pre-scientific societies develop myths concerning the miraculous and supernatural; scientific societies develop myths about experience, which is presumably what Bidney means by "secular myths". Bultmann (1953) acknowledges that, read literally, myth is about the physical world, is incompatible with science, and should be rejected as uncompromisingly as Tylor (ibid.) and Frazer (ibid.) rejected it. Bultmann proposes reading myth symbolically. Taken symbolically, or 'demythologized', myth is no longer about the external world. It is now about the place of human beings in the world, Myth no longer explains but describes, and describes not the world itself but humans experience of it. It describes the alienation from the world that humans experience before turning to God and the athomeness in the world that they experience upon turning to God. It depicts the human condition.

Jonas (1963) seeks to show that ancient myths retain a message for moderns rather than to show that moderns have myths of their own. For Jonas, myth, read symbolically, describes the alienation of humans from the world prior to their acceptance of God. Because ancient Gnosticism, unlike mainstream Christianity, sets immateriality against matter, humans remain alienated from the material world even after they have found the true God. In fact, the true God can be found only by rejecting the false god of the material world. Grostics overcome alienation from this world only by transcending the world. Eliade (1968), myth explains the origin of both physical and social phenomena, just as for Malinowski. And the explanation is that a god - though never a mere human - brought it about. For Eliade, in contrast to Malinowski, myth is a part of religion. But the payoff of myth is not reconciliation to the unpleasantries of life. Quite the opposite: the payoff is escape from the world and return to the time of the origin of whatever phenomenon is explained. Myth is like a magic carpet. Because all religions, according to Eliade, preach that gods were closer at hand in days of yore than now, to be whisked back in time is to be able to brush up against the god at work in the myth. Myth is a medium for encountering God.

As Blumenberg (1985) has shown in some detail, mythos's essential mode of functioning is "theatrical." Mythos presents the world as high drama, constructing stories that help make the listener feel at ease in the world: "Myth represents a world of stories that localizes the hearer's standpoint in time in such a way that the fund of the monstrous and the unbearable recedes in relation to him'. This theatrical mode of 
orientation endows the world with what Blumenberg calls "significance," a transcendental, pre-cognitive framing or " charging" of the experiential horizon with a "valenced" sense of purposiveness or meaningfulness that is prior to the determination of any specific purpose or meaning (Rose, 2007).

For Phillip Cary (2011): "what the soul is, what makes the human soul different from the beasts and what happens to it after death was a matter or myth, speculation, and disagreement". For Segal (2011), myth can be true as well as false, but explaining the tenacity with which myth is held counts even more. Myth does not hold a tighter grip when true than when false.

Myths, as explanations of the cosmos and how to live, are parallel to science in many ways. Yet because of their differences from science, they often appear insignificant, whimsical, useless, or primitive to contemporary people. Many people lament the decline of myths, because they promise the moral guidance and comfort that helps enrich life. For these reasons, many people remain interested in myths andsseek to revive or revere them. Additionally, myths continue to intrigue us because of their rich symbolic, metaphorical, and narrative appeal. Some people believe classical music, movies, and even novels have filled the places myths used to occupy culturally. In our post-modern world many people believe myths exist in new, combined, or revived forms. One of the functions of all art is to reconcile us to paradox.Another is to suggest fundamental patterns of life and the universe. Even if they are no longer associated with religious rituals, belief systems, or primordial moments of creation, "myths" of heroic characters who mediate the troubling paradoxes of life will always compel us and can, we believe, still be found in our culture.

Myths may be enacted through rituals and believed in absolutely, but they usually do not have physical effects in the real world, as, in leading to new technology for building cars or providing medical treatment. People may believe they are cured through faith, and they may find important value-laden sentiments in myths, but these "real world results" are neither empirical nor usually repeatable. Although science differs from myth in offering actual, testable control over the environment and producing real, repeatable results in the world, science is not completely divorced from myth. Many scientific theories are presenfed or understood in narrative form, which often end up sounding remarkably mythic.

As myth gives meaning and purpose to even the most seemingly disparate and fragmented elements of culture, so it affirms life processes of change and refashioning. Myth provides the ideal values of the culture. Many of western moral values, for example, come from the Jewish-Christian myths. The story of David and Goliath is one reason why we revere courage. Murder and theft are regarded as wrong and evil, as the myth of Moses teaches us. The myth of Noah and the Ark tells us of the consequences of evil and righteousness. To summarize then, myth provides a guide for the individual throughout his life; one that aids him to live in health, strength, and harmony in the particular society in which he was born. For Sylvie Brunel (2008) a critic of the basis of the sustainable development, with its binary vision of the world, can be compared to the Christian mythical vision of Good and Evil, an idealized nature where the human being is an animal like the others or even an alien. Nature - as Rousseau thought - is better than the human being. The human is a parasite, harmful for the nature. But the human is the one who protects the biodiversity, where normally only the strong survive

\section{THE WEINREB'S MYTHICAL DIMENSION}


Mythical systems are concerned with hidden meanings. In classical psychology such meanings were central in the psychology of Freud and Jung especially in their emphasis on the unconscious. Following in this tradition Weinreb (1986) described a mythical dimension that contains symbolic images. In fact, Weinreb maintains that everything in the concrete world is experienced as a mental picture in the mythical dimension. There is nothing in the experienced sensory world that is not related to another imaginary dimension (Figure 1). Such ideas are also part of Celtic culture in which aspects of nature resonate with the cultural imagination.

The mythical dimension has a number of characteristics:

1) Space and time have a different meaning from one we are used to :

a) In terms of space, myths do not contain materials like our ordinary experience; so the images do not work with the same logic, and relations and influences may be magical.

In terms of time, past, present and future may not be separate; so, past present and future may merge, mythic events are not constrained by ordinary time as we know it. In myth, death can be a transformation, where the future, the past and the present exist at one and the same time.

Another important characteristic of the mythical dimension is that not only do things appear differently, but their mythical quality is immediately present. This has implications for their cultural meanings. The entire natural-material world in which we exist may be symbolically meaningful in myth, since all its creatures exist in another dimension. 


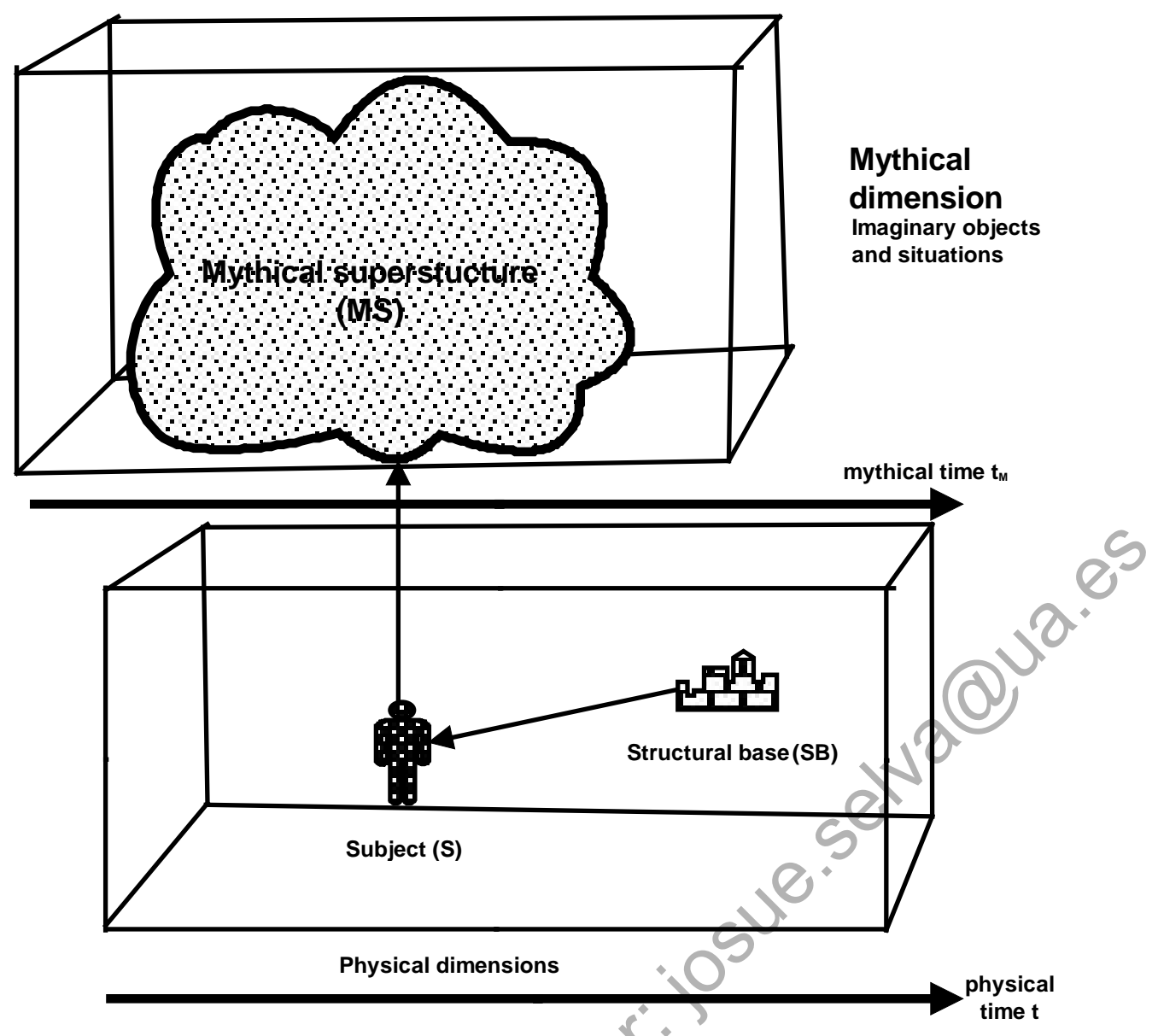

Figure 1: The Weinreb's mythical dimension.

These creatures have meaningful and mutual relationships which are usually hidden from our awareness. Becoming aware of this spiritual meaning requires preparation and a particular awareness and readiness. Such preparation and the resulting awareness provide rich cultural meanings that can transform our personal experience.

2) We might consider the mythical dimension as the Whole, and concrete reality as Part. However, this part is only partly in human consciousness, since people who focus in their communication on the mythical dimension will begin to see the material world in its larger context. Although people's experience is naturally very varied, the unifying nature of the mythical dimension may unify a person's vision of the world, whether this be in a truly mythic way or in way characteristic of another spiritual vision. There may be stages in this process leading from polytheistic myths to monotheistic myths: polytheistic myths being prior to a unifying vision of reality, with a single Divine Being.

3) The mythical dimension is closely connected with people's imagination and spiritual life. Where Jung draws out these ideas with his unconscious, Weinreb's emphasises the mythical dimension. Indeed, the unconscious includes both personal and cultural content of which we may but are not necessarily aware.

4) As Freud realized we can become aware of unconscious meanings through analysis of our dreams. Our dreams are the products of our minds at moments when we are not exercising any cognitive control. Whether the content is culturally or personally determined is an open question, but we can be sure that 
in some way the system of memories of which we are unaware emerge and so we have access to mental issues that are otherwise hidden..

5) Weinreb (1986) claims that the myths derive, in principle, from one source of inspiration and therefore can be approached using the same commentary methods: he applied this principle to the Bible, the Oral Tradition as well as to the New Testament. Weinreb's commentary on the New Testament has typological, mythical and archetypal features in accordance with the aforementioned principles: it gives the New Testament a universal dimension which transcends Christianity.

The religious behavior is as practical as the technical behavior; it assures a man integration to a world that exceeds him and with that he understands both physics and the metaphysical. To each stage of this integration there corresponds a phase of religious behavior. While the old phases of the beliefs have extended until the present, in each historical stage a new phase was added that dominated the others.

In what follows, distinctions are made between what the individual knows, and what the culture or society knows. The mathematical model that is proposed must take account of both classical logic and what is called paralogic. This corresponds to the curious facility of the human mind to take shortcuts and make associations that are not logical (Schweder, 1996). Such illogical human moves are called heuristics. The social knowledge considered here consists of superstructures of myths and beliefs (doxical superstructure). Mathematical models must take account of an individual's incomplete knowledge of objects and events and their possibility and contingency, knowledge is after all psychological and not logical. These terms will be clarified in the sections that follow on the modelling of both mythical thinking and the beliefs that myth contains.

\section{MODAL CHARACTERISTICS OF THE MYTHS}

A belief system is a set of related ideas, learned and shared which has some permanence in time and space, and to which individuals and/or groups exhibit some commitment (Usó-Doménech et al., 2009 a,b; Nescolarde-Selva and Usó-Doménech, 2013ª,b; UsóDoménech and Nescolarde Selva, 2012). The conditions of permanence, commitment, and connectedness are variable characteristics through which we expect belief systems to be related to social organization. Any belief system will be formed by two essential levels:

1) An ideal or abstract level.

2) A material level or text.

Substantive beliefs (Nescolarde-Selva and Usó-Doménech, 2013,d Usó-Doménech and Nescolarde Selva, 2012) constitute the axioms of the system, while many derived beliefs will constitute their theorems.

Let $\left\{M_{i}\right\}_{i=1, \ldots, n}$ be a set of mythical dimensions and $\mathbf{L}$ be a language. The terms $\mathrm{S}$ in this language are of the following form $s_{1}, s_{2}, \ldots ., s_{n}$. The terms D are the following form $d_{1}, d_{2}, \ldots . ., d_{m}$. 
In a set $\mathrm{S}$ of substantive beliefs, we have the following characteristics:

1) The terms $S_{n}($ for $n=0,1,2, \ldots, n)$ are atomic sentences.

2) The terms $d_{m}$ (for $m=0,1,2, \ldots, n s$ ) are atomic sentences.

3) The terms $\mathrm{s}$ and $\mathrm{d}$ belonging to sets $\mathrm{S}$ and $\mathrm{D}$ are belief sentences.

4) $S$ is consistent just if it would be possible for them all to be true together: that is, if they are either in fact all true or could all have been true.

5) $\mathrm{S}$ is inconsistent just if it would be impossible for them all to be true.

6) A term $s \in S$ can also be said to be consistent if it is possible for it to be true.

7) A term $s \in S$ can also be said to be inconsistent if it is not possible for it to be true.

8) An inconsistent belief is said to be self-contradictory, or a contradiction ${ }^{3}$.

9) A term $s \in S$, which could not be false, is said to express a necessary truth.

10) A term $s \in S$, which is not inconsistent and does not express a necessary truth is said to be contingent.

For our intentions, we will apply concepts of Modal Logic.

Let $\mathrm{T}$ be the constant for truth, $\perp$ be the constant for falsity. $\rightarrow, \square, \diamond$ be the signs for conditionality, necessity and possibility respectively. Then:

1) A term $\mathrm{s}$ of the form $\square$ s is true iff $\mathrm{s}$ is true at all $M_{k} \in\left\{M_{i}\right\}_{i=1, \ldots, n}$.

\footnotetext{
${ }^{3}$ A paraconsistent treatment of problems such as a philosophy of religion that accommodates certain antinomian assertions. In doing so, it offers as an underlying logic to build theory, that is not a classical logic like an Aristotelianlogic, but rather a logic that we call a paraconsistent logic.

In religious texts is often very difficult to paraphrase well. It is often forged in a way where the same God and the same context, in relation to the same entities and under the same aspect, has contradictory characteristics such as benign and malevolent, sweet and angry, fearful and kind, inaccessible and accessible, indulgent and severe -not to mention many other contradictions that perhaps could be susceptible to other reinterpretations, less literal and more charitable, and all this in an absolute way without nuances. The more or less obvious meaning of many of these texts and discourses imply that God has each pair of opposite determinations in a special way, owning each to a high degree. The doctrine of coincidentia oppositorum, the interpenetration, interdependence and unification of opposites has long been one of the defining characteristics of mystical (as opposed to philosophical) thought. Whereas mystics have often held that their experience can only be described in terms that violate PNC (the principal of non-contradiction) western philosophers have generally maintained that this fundamental logical principle is inviolable.

An Ionian contradiction to the compound proposition $P \wedge \neg P$, that is the logical conjunction "P and not $\boldsymbol{P}^{\prime}$. For Heraclitus such contradiction can be expressed a truth. An Ionian proposition designate as $\boldsymbol{K}(\boldsymbol{\aleph})$, is an Ionian contradiction $\boldsymbol{P} \wedge \neg \mathbf{P}$ whose truth value is always 1, i.e. $v(\boldsymbol{P} \wedge \neg \boldsymbol{P})=1$.
} 
2) A term $s$ of the form $\diamond \mathrm{s}$ is true iff $\exists M_{k} \in\left\{M_{i}\right\}_{i=1, \ldots, n}$ where $s$ is true.

The set $\left\{M_{i}\right\}_{i=1, \ldots, n}$ collects just those mythical dimensions for which the corresponding term $\mathrm{s}_{\mathrm{n}}$ is true. Term $\mathrm{s}_{\mathrm{n}}$ is true for a mythical dimension $\mathrm{M}_{\mathrm{K}}$ iff $\mathrm{M}_{\mathrm{K}}$ is in $\left\{M_{i}\right\}_{i=1, \ldots, n}$.

Definition 1: A belief system שב is a pair $\left\langle\left\{M_{i}\right\}_{i=1, \ldots, n}, M\right\rangle$ in which $\left\{M_{i}\right\}_{i=1, \ldots, n}$ is a set of mythical dimensions and $\mathrm{M}$ abbreviates a finite sequence $M_{1}, M_{2}, \ldots . M_{n}$ of subsets of $\left\{M_{i}\right\}_{i=1, \ldots, n}$.

Let $\mathrm{s}$ be a term and $\mathrm{M}_{\mathrm{k}}$ be a mythical dimension in a belief system שב = $\left\langle\left\{M_{i}\right\}_{i=1, \ldots, n}, M\right\rangle$. We use the symbolism $F_{\text {MK }}(\mathrm{s})$ as short for $\mathrm{s}$ is true in $2 \boldsymbol{e}$. The following axioms are stated:

Axiom 1: $k^{2{ }^{2}}{ }_{M K}\left(s_{n}\right)$ iff $\exists M_{k} \in \mathrm{M}$ for $\mathrm{k}=0,1,2, \ldots, \mathrm{n}$.

Axiom 2: $F^{2}$ MK $\mathrm{T}$.

Axiom 3: $N o t k^{2}{ }_{\mathrm{MK}} \perp$.

Axiom 4: $F^{2{ }^{2}}{ }_{M K}\left(ך s_{n}\right)$ iff not $k^{2{ }^{2}}{ }_{M K}\left(s_{n}\right)$.

Axiom 5: $F^{2 W}{ }_{M K}\left(s_{i} \wedge s_{j}\right)$ iff both $F^{2{ }^{2}}{ }_{M K}\left(s_{i}\right)$ and $k^{2{ }^{2}}{ }_{M K}\left(s_{j}\right)$.

Axiom 6: $k^{2{ }^{2}}{ }_{M K}\left(s_{i} \vee s_{j}\right)$ iff either $k^{{ }^{W}}{ }_{M K}\left(s_{i}\right)$ or $k^{2{ }^{2}}{ }_{M K}\left(s_{j}\right)$, or both.

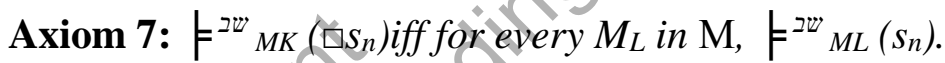

Axiom 8: $={ }^{2 W} M K\left(\diamond s_{n}\right)$ iff for some $M_{L}$ in $\mathrm{M}, k^{2{ }^{2}}{ }_{M L}\left(s_{n}\right)$.

Axiom 9: $F^{2{ }^{2}}{ }_{M K S} \rightarrow s^{\prime}$ iff $k^{2{ }^{2}}{ }_{M K} s$ then $F^{2{ }^{2}}{ }_{M K} s^{\prime}$.

We write $=\mathrm{s}$ to mean that belief $\mathrm{s}$ is valid. A belief $\mathrm{s}$ is valid $=\mathrm{s}$ iff for every belief

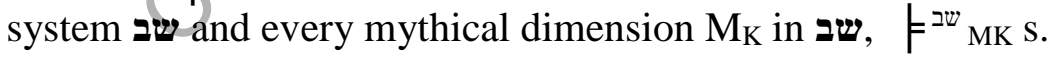

From this we deduce the following theorems

Theorem 1: $\square s \rightarrow s$.

Proof:

It is sufficient to prove that where $\mathrm{M}_{\mathrm{K}}$ is any mythical dimension in any belief system

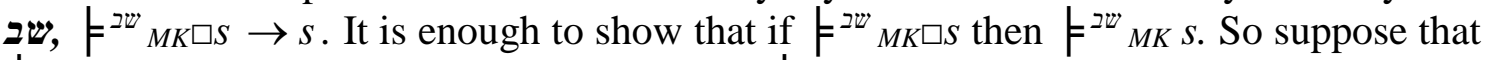
$k^{2 E}{ }_{M K} \square S$. Then by axiom 8 this means that $F^{2 ש}{ }_{M L} S$ for every mythical dimension in ש2. In particular this hold for $M_{K}$. Then $F_{M K} S$. 
Theorem 2 (Principle of Distributivity): $\square\left(s \rightarrow s^{\prime}\right) \rightarrow\left(\square s \rightarrow \square s^{\prime}\right)$.

Proof:

We suppose that $\mathrm{M}_{\mathrm{K}}$ is a mythical dimension such that both $k^{{ }^{2}}{ }_{M K} \square\left(s \rightarrow \mathrm{s}^{\prime}\right)$ and $\boldsymbol{F}^{\mathrm{w}}$ $M K \square S$. For every mythical dimension $\mathrm{M}_{\mathrm{L}}$, both $=^{{ }^{2}}{ }_{M L} s \rightarrow \mathrm{s}^{\prime}$ and $\boldsymbol{F}^{2{ }^{2}}{ }_{M L} \mathrm{~s}$, from which it follows that for every mythical dimension $\mathrm{M}_{\mathrm{L}}, \mathrm{F}^{2{ }^{2}}{ }_{M L} S^{\prime}$. Thus $F^{2{ }^{2}}{ }_{M K} \square S^{\prime}$.

Theorem 3 (Rule of Necessitation): If $\mid$ s then $\vDash \square s$.

Proof:

For suppose that $\vDash$ s, i.e., that $k^{2}{ }^{w} S$ for every mythical dimension. Then $k^{2 w} M K \square S$, which is to say that $=\square s$.

Let $\mathrm{S}_{\mathrm{B}}$ be a believing subject. According to Pietroski (1993) the binary analysis is applied by means of the following requirements:

R1) $S_{B}$ believes that the term $s$ is true exactly when $S_{B}$ believes the sentence signified by $s$.

R2) Property of omnidoxasticity ${ }^{4}$ : If $S_{B}$ believes the terms $s_{1}, s_{2}, \ldots . ., s_{n}$, and $\left\{s_{1}, \ldots ., s_{n}\right\}$ entails $d \in D$, then $S_{\text {B }}$ also believes $d$.

R3) That $s$ signifies a set of mythical dimensions $M_{k} \in\left\{M_{i}\right\}_{i=1, \ldots, n}$ where $s$ is true .

R4) There is some true sentence $\zeta$, which is similar to s.

R5) The truth of any s requires $S_{B}$ to have an appropriate metalinguistic belief.

R6) In the mythical dimensions $\left\{M_{i}\right\}_{i=1, \ldots, n}$, the requirement R5 is dropped by omitting requirement $\mathrm{R} 4$.

R7) In abnormal contexts, such as where determined ideological beliefs are attributed, the requirement R5 is dropped omitting requirement R3.

If $S_{B}$ believes that $s$ is true, it follows that $S_{B}$ believes $\left\{M_{K}\right.$ : $s$ is true in $\left.M_{K}\right\}$.

Example 1: Let $\mathbf{L}$ be the $S_{B}$ 's language. We suppose other language $\mathbf{L}$ '. We consider that $\mathrm{S}_{\mathrm{B}}$ is told that God does not exist is a true $\mathbf{L}^{\prime}$ term, but he has no idea what it means. $\mathrm{S}_{\mathrm{B}}$ still believes that God does exist, but taking his other term in $\mathbf{L}$ ' to be trustworthy, he comes to acquire the new belief that God does not exist is true. So he now believes that set $\mathrm{P}=\left\{\mathrm{M}_{\mathrm{K}}\right.$ : God does not exist is true in $\left.\mathrm{M}_{\mathrm{K}}\right\}$. Consider the term " $S_{B}$ believes that God does not exist", which intuitively is false. If we suppose that this in a mythical

\footnotetext{
${ }^{4}$ Omnidoxicity refers to the unrealistic treatment of believers as “ideal” (Kieron O'Hara et.al. 1995).
} 
dimension where R4 does not apply, then the that-clause denotes the necessarily true term, of which set $\mathrm{P}$ is a subset. Since $\mathrm{S}_{\mathrm{B}}$ believes $\mathrm{P}$, for the Property of omnidoxasticity (R2), he also believes the necessarily true term, and so the term $s$ true. On the other hand, if we adopt the other mythical reading which drops R3, then the that-clause in both cases would denote the same metalinguistic proposition $\mathrm{R}=\left\{\mathrm{M}_{\mathrm{K}}\right.$ : something similar to God does not exist is true in $\mathrm{M}_{\mathrm{K}}$ \}, and so $P \subset M$. As $\mathrm{S}_{\mathrm{B}}$ believes $\mathrm{P}$ by $\mathrm{R} 2$ again he believes $\mathrm{R}$. The conclusion is that for all-admissible interpretations, " $S_{B}$ believes that God does not exist” is true. Then we have a contradiction.

Myth, like any other belief, can be false, but it is not false because it is myth. It is false for the same reasons that other beliefs are false (Gotesky, 1952). Every culture will create and value its own myths, not because it may not be able to distinguish between truth and falsity, but because their function is to maintain and preserve a culture against disruption and destruction. They serve to keep men going against defeat, frustration, disappointment; and they preserve institutions and institutional process. The myths which will be acceptable in a given culture will obviously depend, not merely upon its scientific criteria, but upon the interests and needs of the individuals and groups which compose the society. Depending, of course, on the complexity of the society, theories of levels of truth or kinds of truths will be invented to defend beliefs which may be found inconsistent with what may loosely be called "the facts of experience." Of course, these beliefs (myths) may later be rejected because ways maybe found to test them which may prove them false, or because they are not socially useful. However, in a uniformly scientific culture, myths which contradict experience and reason will obviously be unacceptable.

\section{THE MYTHICAL SUPERSTRUCTURE (MS)}

Deontical Impure Systems (DIS) ${ }^{5}$ are concerned with possibility and necessity, their Superstructure can been divided in two (Usó-Domènech et al. 2009a,b; Nescolarde-Selva and Usó-Doménech, 2013 ${ }^{\mathrm{a}, \mathrm{b}, \mathrm{c}}$; Usó-Domènech and Nescolarde-Selva, 2012):

1) The Doxical Superstructure (DS) is formed by values in fact, political and religious ideologies and culture of a human society in a certain historical time.

2) The Mythical Superstructure (MS) also has been divided into two parts:

${ }^{5}$ Impure sets (Maddy, 1990) are sets whose referential elements (absolute beings) are not counted as abstract objects and have the following conditions: a) They are real (material or energetic absolute beings). b) They exist independently of the Subject. c) S develops p-significances on them. d) True things can be said about them. e) Subject can know these true things about them. f) They have properties that support a robust notion of mathematical truth. A simple impure system-linkage $\Sigma \equiv(\mathrm{M}, \mathrm{R})$ is a semiotic system consisting of the pair formed by an impure object set $\mathrm{M}$ the elements of which are p-significances (relative beings) of entities belonging to Reality (absolute beings) or certain attributes of these, and a set of binary relations, such that $\mathrm{R} \subset \mathrm{P}(\mathrm{M} \times \mathrm{M})=\mathrm{P}\left(\mathrm{M}^{2}\right)$. That is $\forall \mathrm{r} \in \mathrm{R} / \mathrm{r} \subset \mathrm{MXM}$ being $r=\left\{\left(x_{i}, x_{j}\right) \in M \times M \mid x_{i}, x_{j} \in M\right\}$. An impure system-linkage defined within an impure object set $\mathrm{M}$ is a simple system $\mathrm{S}=(\mathrm{M}, \mathrm{R})$ or a finite union of simple systems-linkage $\Sigma=\cup_{\mathrm{i}=1}^{\mathrm{n}_{\mathrm{i}}} \Sigma_{\mathrm{i}}$ such that $\Sigma_{\mathrm{i}}$ are simple systems. This shall be denoted as $\Sigma \equiv(\mathrm{M}, \mathrm{R})$ such that $\mathrm{R} \subset \mathrm{P}\left(\cup_{\text {finite }} \mathrm{M}^{2}\right)$. A Deontical system is an organization of knowledge on the part of the subject $S$ that fulfils the following conditions: a) Other subjects (human beings) are elements of the system. b) Some existing relations between elements have Deontic modalities. c) There is purpose (purposes). 
a) $\mathrm{MS}_{1}$ containing the mythical components or primogenial bases of the ideologies and cultures with ideal values.

b) $\mathrm{MS}_{2}$ containing ideal values and utopias that are the wished and unattainable goals of belief systems of the Doxical Superstructure (DS).

These ideas are summarized in the following diagram (Figure 2):

There is a double distortion in the ideological phenomenon concerning the opposition between the significance of the real object (relative being) and the reality of this same object (absolute being). Then, the relation between the structural base SB and Superstructures (DS and MS) can be considered for each one of the facts that have been isolated like components in one or another symbolic system. There are a series of correspondences and each one grasps a social reality.

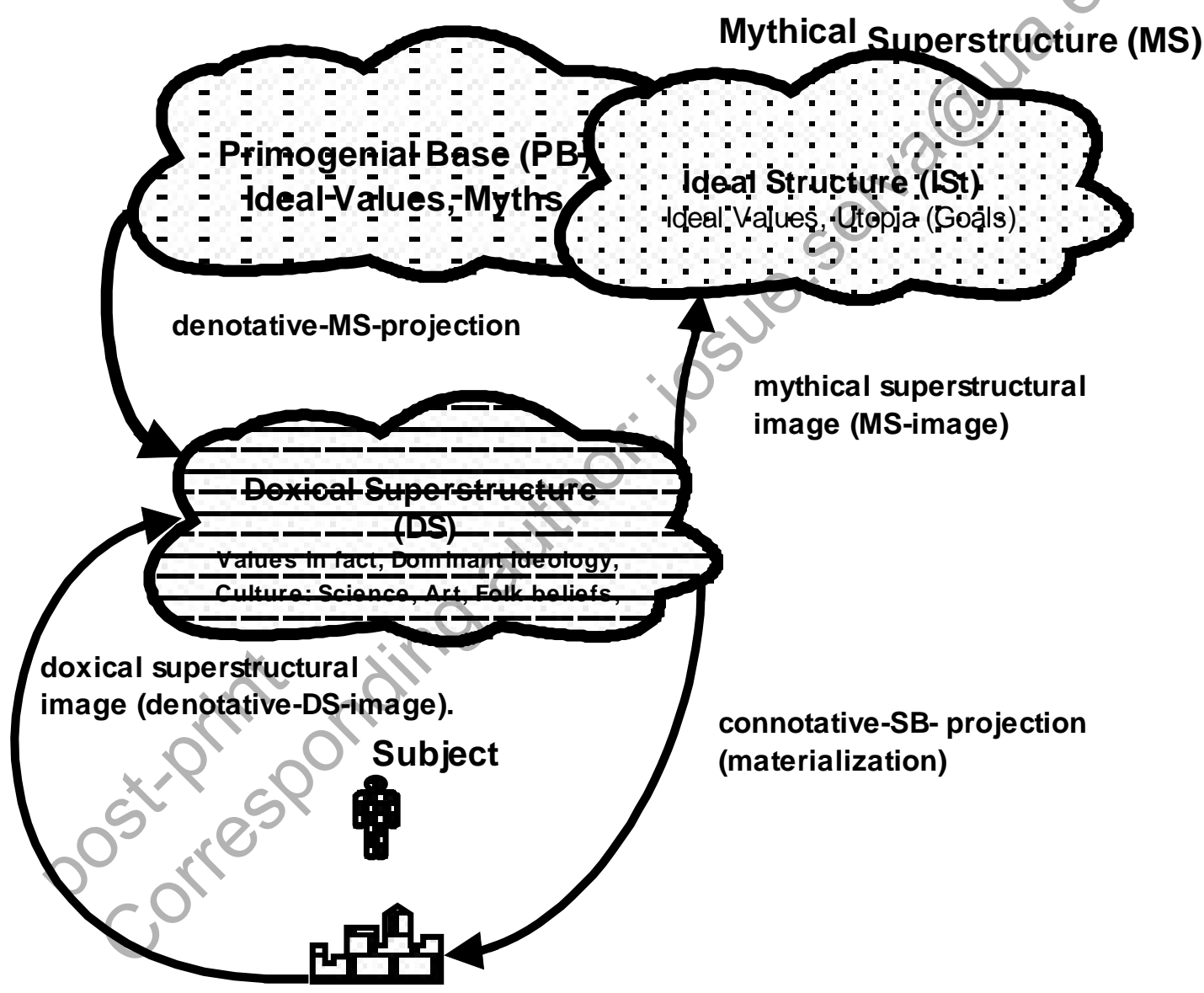

Structural Base

Figure 2: Structural base and superstructures.

We will call the set of doxical superstructural significants $\zeta_{D}$ (Usó-Domènech. and Nescolarde-Selva, 2012): that is to say, the part of the signs that have been limited by the observer Subject, when establishing the borders of the determinate Ideological Doxical Superstructure (IDS) that "cover" the determinate social structures. Let $L_{M}$ be the set of possible mythical superstructure individuals, that is to say, the totality of 
abstract mythical objects/persons and relations belonging to the Mythical Superstructure (MS). Let $I_{D S}=\left\{i_{D S}\right\}$ be the set of possible deontical superstructure individuals, that is to say, the totality of abstract objects/persons and relations including within the doxical superstructure IDS of system $\Sigma$

There is a mythical superstructural significance (MS-significance) signified as $s_{\Sigma}^{M}$ that is a function of the maps' set $\zeta_{D}$ as a subset of $\mathrm{L}_{\mathrm{M}}$. MS-significances are the meaning in the mind of the Subject of the elements belonging to the Mythical Superstructure. MSsignificance $s_{\Sigma}^{M}$ has in $\zeta_{D}$ an attribution in respect to the abstract relation $R_{i}^{k}$ belonging to DS if $R_{i}^{k} \in S_{\Sigma}^{M}\left(\zeta_{D}\right)$. Normally, any actor Subject confuses IDS-significances and MS-significances.

Corresponding to some certain MS-significance $s_{\Sigma}^{M}$ in MS, there is a single IDSsignificance $\overrightarrow{s_{\Sigma}^{M}}$ to which we will call denotative-IDS-projection (IDS-projection) of the MS-significance $s_{\Sigma}^{M}$ in the doxical superstructure (DS) and that $\overrightarrow{s_{\Sigma}^{M}}$ for each $\zeta_{D}$ and for each $i_{D S} \in I_{D S}, \quad i_{D S} \in s_{\Sigma}^{M}\left(\zeta_{D}\right)$, iff $i_{D S}^{C} \in s_{\Sigma}^{M}\left(\zeta_{D}\right)$. The totality of IDS-projections on Doxical Superstructure (DS) form a subsystem of the systems of beliefs (among them the dominant ideology) that conform to the Doxical Superstructure. The IDS-projection of the MS on the Doxical Superstructure (DS) is for the Subjects the primitive and subconscious explanation of the ideal and abstract doxical superstructure. Any dominant ideology has as a "foundation" a myth or residual ideology, which projects on the Doxical Superstructure. For each IDS-significance $s_{D}$ there is a single MS-significance $\varepsilon_{M}$ that we will call the mythical superstructural image (MS-image) of $s_{\Sigma} M$ in MS and that $\varepsilon_{M}\left(\zeta_{D}\right)=\left\{R_{i}^{k}, s_{D} \in R_{i}^{k}\right\}$.

The part of the Mythical Superstructure containing myths constitutes the Primogenial Base (PB) of the Doxical Superstructure (DS).

The mythical superstructural image formed in the MS constitutes for the actor Subject (considered here as a believer) the last goal of his belief, that is to say, the Utopia. The totality of the MS-images reflected in the utopic part of the Mythical Superstructure (MS) forms an Ideal Structure (Utopic Structure ISt) that constitutes the final and unattainable goabofall ideology.

IDS-significance and its MS-image are equivalent, that is to say, that for $\zeta_{D}$ and for each abstract relation $R_{i}^{k}, R_{i}^{k}$ has $s_{D}$ in $\zeta_{D}$, iff $R_{i}^{k}$ has $\varepsilon_{M}$ in $\zeta_{D}$. This assertion leads us to $s_{D} \in R_{i}^{k}$ iff $R_{i}^{k} \in \varepsilon_{M}\left(\zeta_{D}\right)$.

Any Subject $S$ has or constructs a certain language $\boldsymbol{L}_{\boldsymbol{M}}$ containing denotative-IDSpredicates (IDS-predicates) and mythical structural predicates (MS-predicates). A denotative-IDS-predicate (IDS-predicate) $P^{D S}$ is that predicate belonging to $\mathbf{L}_{\mathbf{M}}$ that express (names) one IDS-significance $S_{D}$. Any mythical structural predicate (MSpredicate) $P^{M}$ is that predicate belonging to $\mathbf{L}_{\mathbf{M}}$ that expresses (names) one MSsignificance $\varepsilon_{M}$

Let us suppose that observer subject S names (in $\boldsymbol{L}_{\boldsymbol{M}}$ ) like $v^{*}$ any abstract relation $R_{i}^{k}$, then: 
1) $P^{D S} v^{*}$ is true in $\zeta_{D}$ if the abstract relation $R_{i}^{k}$ that $v^{*}$ express in $\mathbf{L}_{\mathbf{M}}$, has $S_{D}$ in $\xi_{D} \cdot$

2) $P^{M} v^{*}$ is true in $\zeta_{D}$ if the abstract relation $R_{i}^{k}$ that $v^{*}$ express in $\mathbf{L} \mathbf{M}$, has $\varepsilon_{D}$ in $\zeta_{D}$.

The relation between one IDS-significance and its MS-image induces equivalence between the predicates of language $\boldsymbol{L}_{\boldsymbol{M}}$ in the following way:

Property 1: If $P^{D S}$ express $s_{D}$ and if $P^{M}$ express $\varepsilon_{M}$ in $L_{M}$, then if $\boldsymbol{v}^{*}$ names one abstract relation $R_{i}^{k}, P^{D S} v^{*}$ is true iff $P^{M} v^{*}$ is true.

We propose : For each $\zeta_{D}$ and for each abstract relation $R_{i}^{k}$ if $R_{i}^{k}$ there is in $\zeta_{D}$ then $R_{i}^{k} \in \varepsilon_{M}\left(\zeta_{D}\right)$ iff $R_{i}^{k} \in \vec{s}_{\Sigma}^{M}\left(\zeta_{D}\right)$ Logically, the idea is that $\overrightarrow{s_{\Sigma}^{M}}$ is the only IDSsignificance that agrees with MS-significance $s_{\Sigma}^{M}$ in relation to all the possible existing abstract relations. Then we may say that:

Property 2: In the language $L_{M}$ if $P^{M}$ expresses (it names) $s_{\Sigma}^{M}$ and if $P^{D S}$ expresses (it names) $\overrightarrow{s_{\Sigma}^{M}}$, then if $v^{*}$ expresses (it names) an existing abstract relation, then $P^{D S} \rho^{*}$ is true iff $P^{D S} v^{*}$.

Figure 3 represents the hypothesis of the relationship between the structural basedoxical and the mythical superstructures in a second approach. The Ideal will be formed by the Mythical Superstructure $(P B \cup I S t)$ and the present experience formed by the Ideological Doxical Superstructure (IDS) and the Structural Base (SB).

$\zeta_{\mathrm{D}}$ is the set of doxical superstructural signifiers, that is to say, the parts of signs that have been limited by the observer Subject when establishing the borders of the determinate Ideological Doxical Superstructure "covering” a determinate Structural Base (SB). Let $L_{P B}$ be the set of possible primogenial bases (belonging to the Mythical Superstructure) individuals, that is to say, the totality of abstract mythical objects and relations belonging to the Primogenial Base Mythical Superstructure (PB). Let $L_{I S t}$ be the set of possible ideal structures (belonging to Mythical Superstructure) individuals, that is to say, the totality of abstract mythical objects and relations belonging to the Ideal Structure Mythical Superstructure (ISt). Let $I_{D S}=\left\{i_{D S}\right\}$ be the set of possible deontical superstructure individuals, that is to say, the totality of abstract objects/persons and relations included within the Ideological Doxical Superstructure IDS.

The primogenial base mythical superstructural significance (PBMS-significance) is denoted as $s_{\Sigma}^{P B M}$ and is a function that maps the set $\zeta_{D}$ to a subset of LPB. PBMS- 
significances are the meaning in the mind of the Subject of the elements belonging to the Primogenial Base Mythical Superstructure. The ideal structure mythical superstructural significance (IStMS-significance) is denoted as $s_{\Sigma}^{\text {IStM }}$ and is a function that maps set $\zeta_{D}$ to a subset of $\mathrm{L}_{\text {Ist. }}$. IStMS-significances are the meaning in the mind of the Subject of the elements belonging to the Ideal Structure Mythical Superstructure. PBMS-significance $s_{\Sigma}^{P B M}$ have in $\zeta_{D}$ an attribution in respect to the abstract relation $R_{i}^{k}$ belonging to IDS if $R_{i}^{k} \in s_{\Sigma}^{P B M}\left(\zeta_{D}\right)$ IStMS-significance $s_{\Sigma}^{I S t M}$ has in $\zeta_{D}$ an attribution in respect to the abstract relation $R_{i}^{k}$ belonging to IDS if $R_{i}^{k} \in s_{\Sigma}^{I S t M}\left(\zeta_{D}\right)$.

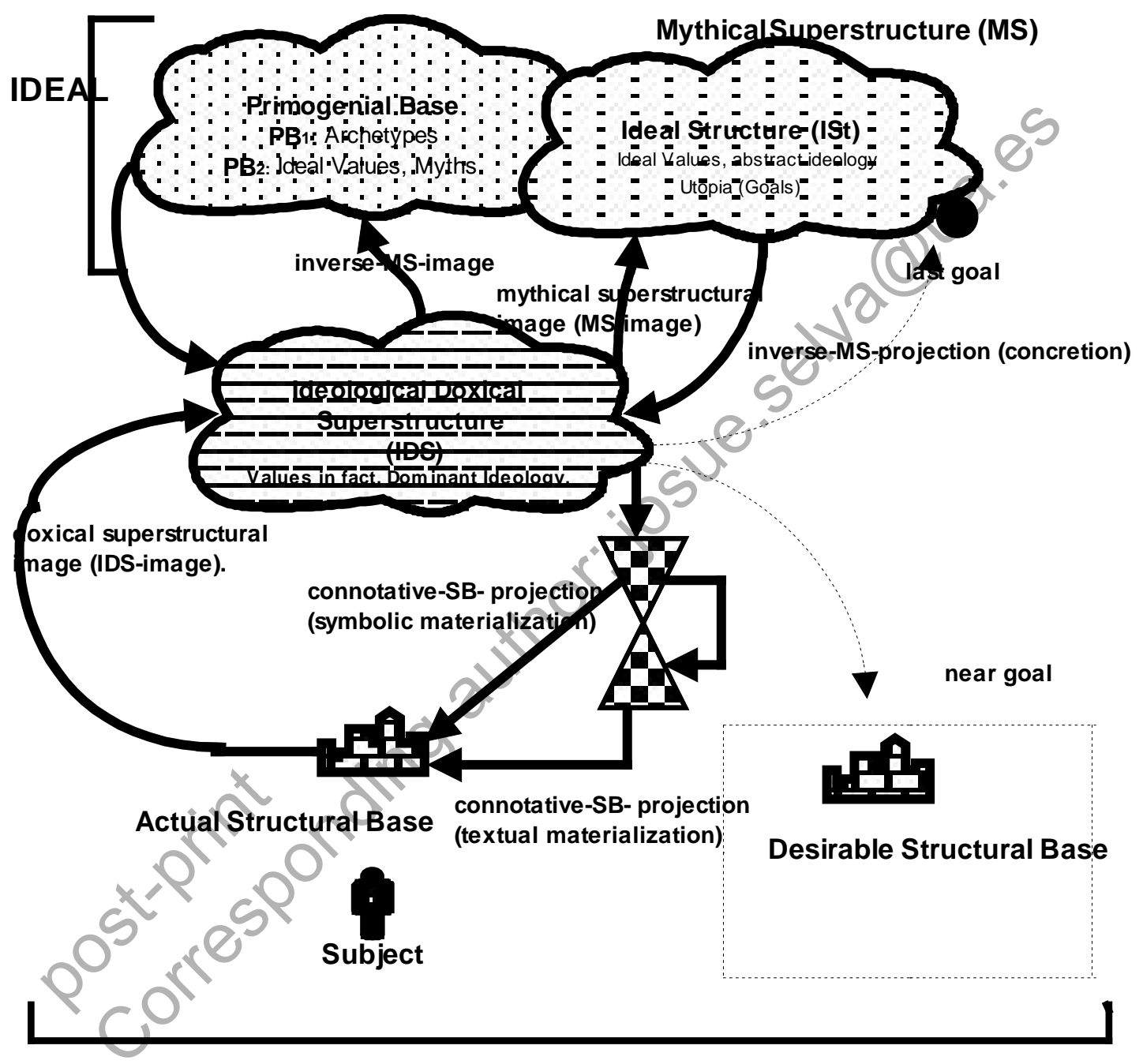

\section{ACTUAL}

Figure 3: Hypothesis of the relationship between structural base-doxical and mythical superstructures on second approach.

Then:

1) For some IDS-significances $s_{D}$ there is a single PBMS-significance $s_{\Sigma}^{P B M}$ that we will call the inverse-MS-image (PB-image) of $s_{\Sigma}$ in PB and that $s_{\Sigma}^{P B M}$ $\varepsilon_{\Sigma}^{P B M}\left(\zeta_{D}\right)=\left\{R_{i}^{k}, S_{D} \in R_{i}^{k}\right\}$. 
2) Corresponding to each IStM-significance $s_{\Sigma}^{I S t M}$ in ISt, there is a single IDSsignificance $s_{\Sigma}^{I \overrightarrow{S T M}}$ which we will call the inverse-MS-projection (IDS-projection) of the ISt-significance $s_{\Sigma}^{I S t M}$ in the doxical superstructure (IDS) and that $\overrightarrow{s_{\Sigma}^{I S t M}}$ for each $\zeta_{\Sigma}$ and for each $i_{D S} \in I_{D S}, \quad i_{D S} \in s_{\Sigma}^{\overrightarrow{I S t M}}\left(\zeta_{D}\right)$, iff $i_{D S}^{C} \in s_{\Sigma}^{I S t M}\left(\zeta_{D}\right)$.

3) The inverse-MS-image (PB-image) can have an exchange, readjustment or different interpretation from myths and ideal values, and from the primogenial foundation of any ideology and belief system.

4) Inverse-MS-projections (IDS-projections) constitute "adjustments" on ideologies and belief systems.

5) Inverse-MS-projections (IDS-projections) constitute a process of concretization or passage of the ideal abstract ideology to the concrete ideology that is perceived with immediate form in relation to its opposite ideal.

We consider the Ist-Mythical Superstructure and The Doxical Superstructurê (IDS) like two alysidal sets with unequal cardinal number of alysidal elements (Figure 4).

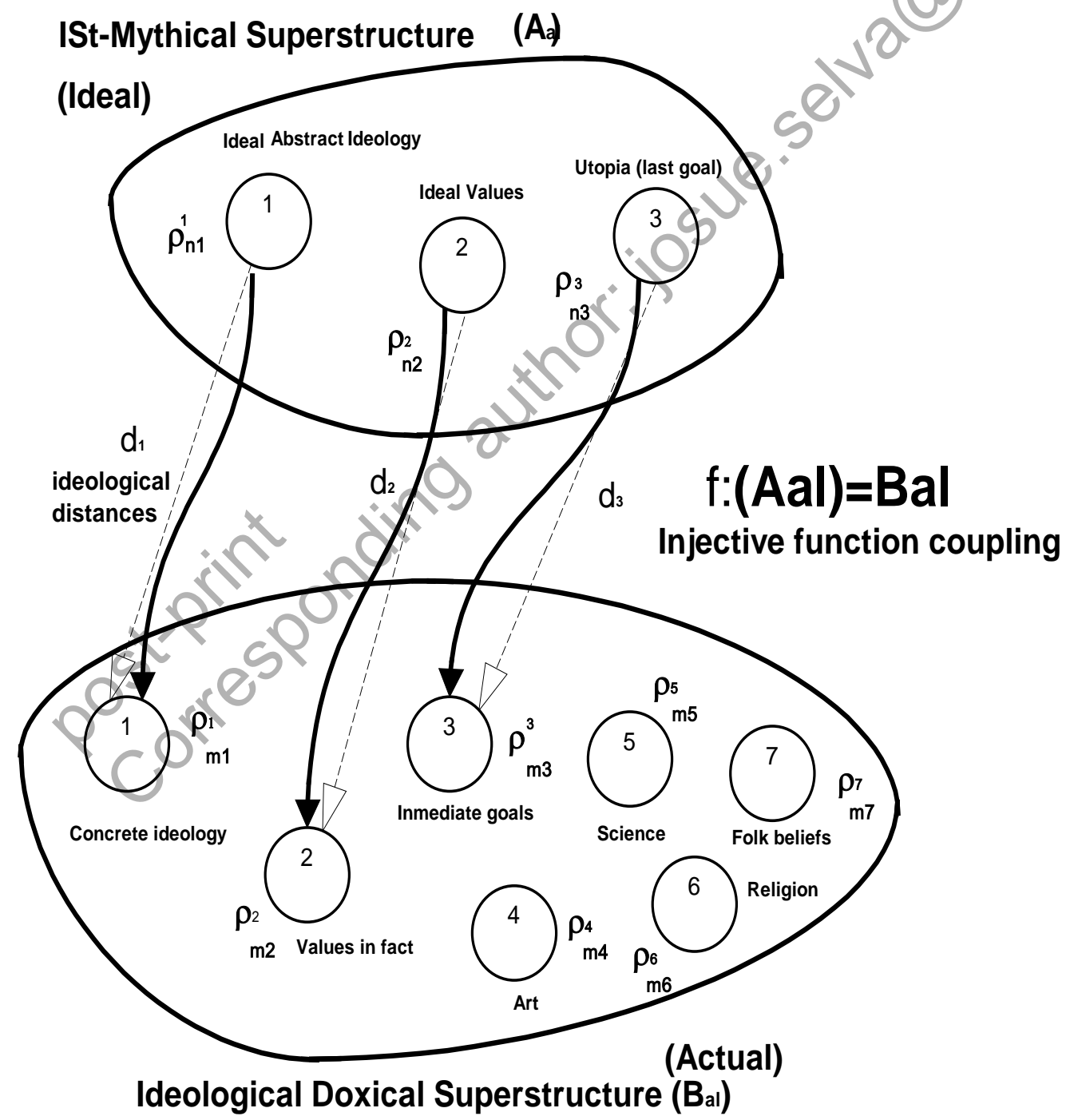

Figure 4: Case of two alysidal sets with unequal cardinal number of alysidal elements. 
We call $\mathrm{A}_{\mathrm{al}}$ and $\mathrm{B}_{\mathrm{al}}$ to two alysidal sets (ISt-Mythical Superstructure and Ideological Doxical Superstructure). By simplification, we suppose that $A_{a l}$ has three alysidal elements, $\left(\rho_{n 1}^{1}, \rho_{n 2}^{2}, \rho_{n 3}^{3}\right)$ corresponding to the Ideal Abstract Ideology, Ideal Values and Utopia respectively. $\mathrm{B}_{\mathrm{al}}$ has alysidal w elements $\left(\rho_{n 1}^{1}, \rho_{n 2}^{2}, \rho_{n 3}^{3}, \ldots ., \rho_{n w}^{w}\right)$ corresponding to the Concrete Ideology, Values in fact, Immediate goals, Art, Science, Folk beliefs, Religion and so on. Subscripts $n_{1}, n_{2}, n_{3}, m_{1}, m_{2}, m_{3}, \ldots, m_{w}$. correspond to substantive beliefs considered like nodes in the theory of Alysidal sets. The coupling function $f\left(A_{a l}\right)^{3 X w}=B_{a l}$ is an injective coupling function ${ }^{6}$. In Alysidal Algebra (NescolardeSelva et al, 2012 ${ }^{\mathrm{a}, \mathrm{b}, \mathrm{c}}$; Nescolarde-Selva and Usó-Doménech, 2012; Usó-Doménech and Nescolarde-Selva, 2012), each alysidal element is a chain formed by $n$ interrelated elements (nodes). In this case, the nodes are substantive beliefs interrelated withrabstract relations.

Example 2: We consider the Abstract Ideology belonging to ISt-Mythical Superstructure and the Dominant Ideology belonging to the Doxical Superstructure as two alysidal sets with a single element (Figure 5).

\footnotetext{
${ }^{6}$ A coupling function is a correspondence between two Alysidal sets $A_{a l}$ and $B_{a l}$ a map $f_{a l}: A_{a l} \rightarrow P\left(B_{a l}\right)$ from the elements(chains) of the Alysidal set $A_{a l}$ to the power set of $B_{a l}$ (Nescolarde-Selva et.al. 2012 ${ }^{\mathrm{a}}$ ).
} 
ISt-Mythical Superstructure

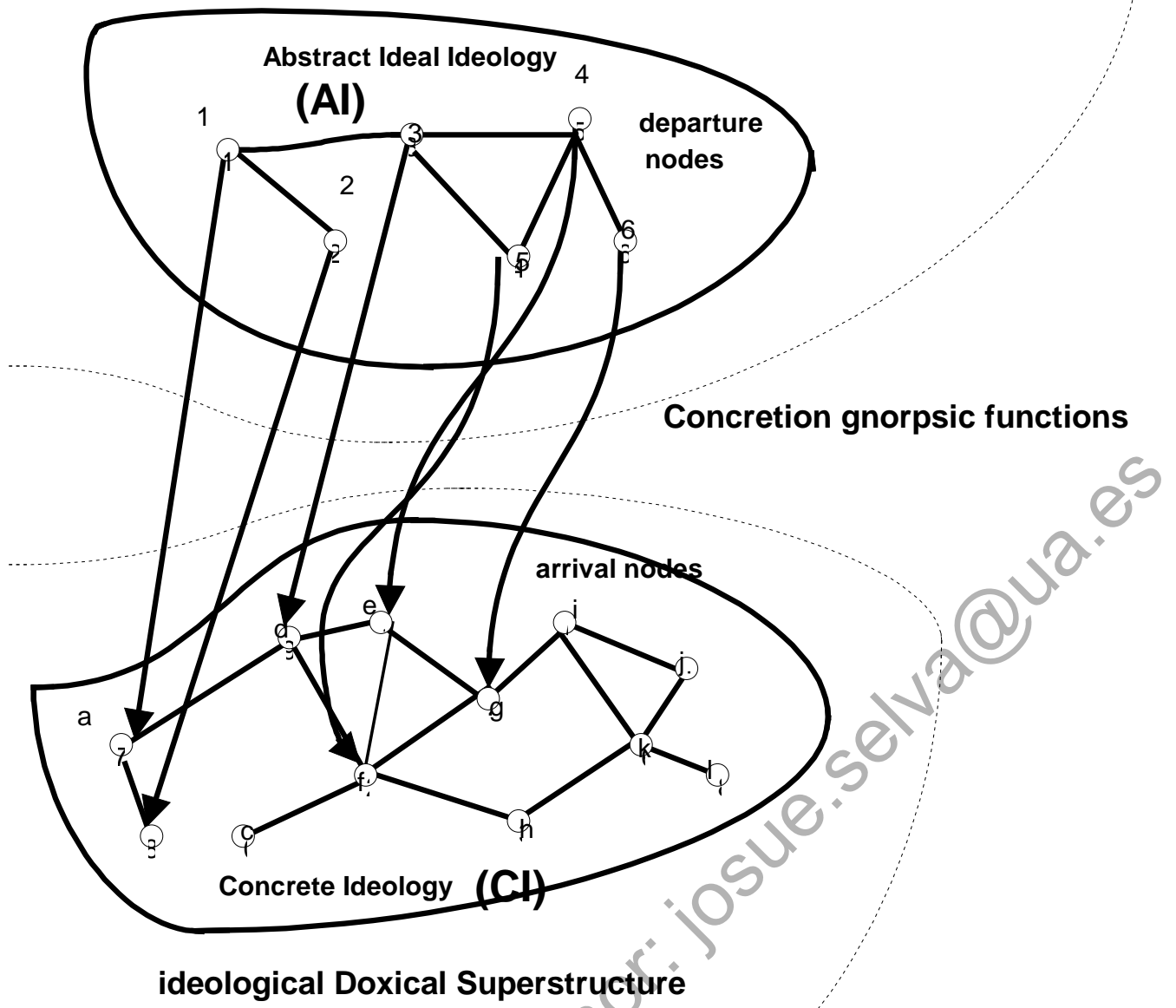

Figure 5: Case of two alysidal sets with a single element.

Nodes are substantive beliefs (Nescolarde-Selva and Usó-Doménech, 2013 ${ }^{\mathrm{c}}$ ) and binary relations are abstract relations between substantive beliefs. In figure 5 the following pairs have formed:c(1, a), (2, b), (3, d), (4, e), (5, f), (6, g).

Abstract ideology will be the domain and concrete ideology will be the co-domain.

In AST if one alysidal element $\wp_{i}^{k}$ of $\mathrm{A}_{\mathrm{al}}$ has n nodes and the alysidal element $\wp_{j}^{l}$ of $\mathrm{B}_{\mathrm{al}}$ has $m$ nodes, the space of possibilities of coupling will be nxm. Nevertheless, in this space of possibilities, a single one "is chosen" as much by the alysidal element $\wp_{i}^{k}$ as by the $\wp_{j}^{l}$. The other possibilities are rejected, however if alysidal element $\wp_{j}^{l} \in B_{a l}$ "knew" that in that certain node it must make a coupling, we will have to define a function of 
knowledge or gnorpsic function ${ }^{7}$ (of the Greek $\gamma v \omega \rho \psi i ́ \alpha$ : to know) (Nescolarde-Selva et al, 2012 ; Nescolarde-Selva and Usó-Doménech, 2012) associated to the connection between alysidal element $\wp_{i}^{k} \in A_{a l}$ and the $\wp_{j}^{l} \in B_{a l}$. The gnorpsic function ${ }_{n_{i}}^{{ }^{m_{j}}} f \wp_{i}^{k} \rightarrow \wp_{j}^{l}$ is the function that determines that node $n_{\mathrm{i}}$ (departure node) of alysidal element $\wp_{i}^{k} \in A_{a l}$ that is connected with node $\mathrm{m}_{\mathrm{j}}$ (arrival node) of the alysidal element $\wp_{j}^{l} \in B_{a l}$. Subindex $\mathrm{n}_{\mathrm{i}}$ indicates the departure node, supraindex $\mathrm{m}_{\mathrm{j}}$ the of arrival node and supraindex $\omega$ the order of coupling.

If connection of $n_{i}$ (departure node) is only with an only arrival node $m_{j}$, the function will be mono-gnorpsic and we denote it as ${ }^{{ }^{m_{j}}} f \wp_{n_{i}} \wp_{i}^{k} \rightarrow \wp_{j}^{l}$. If the connection of $n_{i}$ (departure node) is with two arrival node $m_{j}, m_{k}$, the function will be bi-gnorpsic and we denote it as $\stackrel{m_{j}, m_{k}}{2} f \wp_{n_{i}}^{k} \rightarrow \wp_{j}^{l}$. If connection of $n_{i}$ (departure node) has only three arrival nodes $\mathrm{m}_{\mathrm{j}}, \mathrm{m}_{\mathrm{k}}, \mathrm{m}_{\mathrm{l}}$ the function will be tri-gnorpsic and we it denote as ${ }_{n_{i}, m_{k}, m_{l}} f \wp_{i}^{k} \rightarrow \wp_{j}^{l}$. If the connection of $n_{i}$ (departure node) has many arrival nodes $m_{j}, m_{k}, m_{l}, \ldots, m_{\omega}$ the function will be poli-gnorpsic and we it denote as $\wp_{j}^{m_{j}, m_{k}, \ldots, m_{\omega_{j}}} f \wp_{i}^{k} \rightarrow \wp_{j}^{l}$. In the case that we are considering, we have a mono-gnorpsic function ${ }^{m_{j}} f \wp_{n_{i}} \wp_{i}^{k} \rightarrow \wp_{j}^{l}$, but with a special meaning: the concretization of the ideals with concrete substantive beliefs. Let AI and $\mathrm{CI}$ be the abstract ideal and concrete ideologies so that $A I \in A_{a l} \wedge C I \in B_{a l}$

A concretization function that we denote as $f_{n_{i}}^{m_{j}}(A I)_{\text {con }} \rightarrow C I$ is the mono-gnorpsic function that determines that the substantive ideal belief $n_{i}$ (departure substantive ideal belief) of the alysidal element $A I \in I S t-M y t h i c a l$ Superstructure is connected with the concrete substantive belief mj (arrival concrete substantive belief) of the alysidal element $C I \notin D S$.

Example 3: In the case of figure 5, the concretization functions are:

\footnotetext{
$m_{j}$

${ }^{7}$ A gnorpsic function and we denote as ${ }^{\omega} f \wp_{n_{i}}^{k} \rightarrow \wp_{i}^{l}$ is a function that determines that node $n_{i}$ (departure node) of alysidal element $\wp_{i}^{k} \in A_{a l}$ is connected with node $m_{j}$ (arrival node) of alysidal element $\wp_{j}^{l} \in B_{a l}$ (Nescolarde-Selva, et. al., 2012 ${ }^{b}$ ).
} 


$$
\begin{aligned}
& f_{1}^{a}(A I)_{\text {con }} \rightarrow C I \\
& f_{2}^{b}(A I)_{\text {con }} \rightarrow C I \\
& f_{3}^{d}(A I)_{\text {con }} \rightarrow C I \\
& f_{4}^{e}(A I)_{\text {con }} \rightarrow C I \\
& f \\
& f(A I)_{\text {con }} \rightarrow C I \\
& g \\
& f(A I)_{\text {con }} \rightarrow C I
\end{aligned}
$$

These concretization functions turn ideal substantive beliefs in concrete substantive beliefs.

\section{CONCLUSIONS}

The following conclusions can be drawn:

1) Ideal values, and myth (as residual ideology) belong to the Mythical Superstructure (MS). Its projection conforms, with the image coming from the Structural Base (SB), the dominant ideology and also the values of the Ideological Doxical Superstructure (IDS), and this projects on the SB in the form of actions and conduct and are reflected on the Mythical Superstructure (MS) like utopia, that is the ultimate objective of the ideology.

2) Myth has utopic elements that may reflect "symbolic capital" or ideal social values that are important for social cohesion. In a sense, lack of symbolic capital, on "symbolic decapitation" is equivalent to "demoralization" or the dissolving of the social group.

3) Modern man apparently does not believe in myths but unconsciously they are in the depths of his mind. However ancient myths live in our culture. We find references to those myths in many contemporary words and expressions, such as Pandora's box, Oedipus complex, nymph, and Olympian. Other words derived from mythology include Adonis (from Adonis), aurora (from Aurora), chlorophyll (from Chloris), chronology (from Kronos), discipline (from Disciplina), discord (from Discordia), eros (from Eros), fate (from Fate), fauna (from Faunus), fidelity (from Fides), flora (from Flora), fortune (from Fortuna), fraud (from Fraus), Hades (from Hades), Hell (from Hel), hygiene (from Hygieia), jovial (from Jove), liberty (from Libertas), lunar (from Luna), morphine (from Morpheus), mortality (from Mors), mute (from Muta), narcissism (from Narcissus), nemesis (from Nemesis), ocean (from Oceanus), -and the names of the planets, and of some the months (including Janus for January), etc. Mars (the Roman war god) is remembered in words such as Mars (the planet), March (the month), and martial (as in martial arts). 
4) In terms of 21th century experience, the general thesis that all societies create myths seems highly plausible and, even without laborious evidence, convincing. Our modern society has its own myths. Some authors say that our society lacks a vigorous mythology; they believe that this lack can cause a sense of meaninglessness, estrangement, rootlessness, and the cold brittleness of a life devoid of reverence and awe. Other authors assert that we do have a mythology - in certain concepts (such as "progress") and in our larger-than-life celebrities (e.g., Mother Teresa as the goddess of compassion, Albert Einstein as the god of the intellect and the imagination, and Bill Gates as the god of commerce). The media enlarges certain people to mythical proportions, and we each do the same individually (often by projecting the "Hero" archetype onto other people). Corporations have a mythology, in their "corporate culture." There is a mythology in every group -- our social club, our family, our profession, our subculture, our ethnic group, our religion and denomination, our city, our neighborhood, our friendships, etc. Our mythology changes as our culture changes, from one generation to the next, from one presidential administration to the next, from one decade to the next.

5) There are primitive myths, tribal beliefs, sometimes apprehended and always just below the surface, waiting for a time when to appear, waiting for suitable social or economic circumstances or for a time for a charismatic leader to give a new life to the group. Aryan myth led to World War II and the extermination camps. The myth of the proletariat led to tyranny, misery and Gulag. Islamic myth has led the Muslim world to jihad or holy war with the consequences of terrorism and regional wars that threaten to spread in the world.

6) Closer to common man, movies and TV series are full of mythical figures: Aphrodite is hidden under the perfect lover, Lilith under the assassin and is contrary to the images of motherhood and the female. Hercules and Achilles are features of the hero and Superman. Ulysses is part of the traveler and the Argonauts of space adventures. The myth of the end of the world is presented in movies that speak of deadly viruses, devastating wars, etc. Today, myth often means a simplistic and illusory belief, such as in the expression "the myth of progress" that could transcribe as "simplistic and illusory belief in the inevitability of change for the better".

Granted, however, that science the negative canons or conditions of scientific belief stated above distinguish between myth and non-myth. But by using these canons or conditions, whatever myths are discovered, even though they may be scientific, they will not necessarily be false. They are myths because:

a) they transcend all possible scientific truth criteria, and are thus beyond empirical testing; or

b) while they theoretically conform to truth-criteria, they are not practically testable, as, for example, beliefs which, though not today verifiable, are consistent with the available data; or

c) they serve as basic postulates of a social system to integrate human action and define its procedures, and may consist of rules for evaluating social results and of operations which define socially approved ways of achieving results; while finally,

d) they transcend existing truth-criteria, though at a later time truth-criteria for testing such beliefs may be invented or discovered. Such beliefs (myths) are accepted 
because of their special and general social utility, and their special and general significance for the society and its members.

e) The mathematical approach outlined above provides a step towards specifying the meanings of myths with rigor. We have outlined the broad linguistic and psychological significance of myth, and believe that these models offer a means of being precise with the meaning.

\section{Acknowledgment}

The authors would like to thank Dr. Hugh Gash for his important collaboration in this work, especially English corrections and scientific recommendations.

\section{REFERENCES}

Bascom, W. A. 1965. The Forms of Folklore: Prose Narratives. Journal of American Folklore 78, 3-20.

Bidney, D. 1950. The Concept of Myth and the Problem of Psychocultural Evolution, American Anthropologist. 52(1). 16-26-

Blumenberg, H. 1985. Work on Myth. Trans. Robert MS Wallace. Cambridge, Mass. MIT Press.

Brunel, S. Les enjeux internationaux , entretien avec Sylvie Brunel. France Culture, 11 juin 2008. (In French).

Bultmann, R. 1953. New Testament and mythology. In Kerygma and Myth, ed. H.-W. Bartsch. Trans. R. H. Fuller, vol. I, 1-44. London: SPCK.

Cary, Phillip. 2011. Philosophical and Religious Origins of the Private Inner Self. Zygon: Journal of Religion and Science. 46. 119-32.

Cohen. H. 1869. Mythologische Vorstellungen von Gott und Seele. In Zeitschrift für Völkerpsychologie. IV, 9

Eliade, M. 1968. The Sacred and the Profane. Trans. W. R. Trask. Harvest Books. New York.

Evans, D. (2012) Risk Intelligence. London: Simon and Schuster.

Frazer, J. G. 1922. The Golden Bough. Abridged ed. London: Macmillan [ $1^{\text {st }}$ unabridged edn. 1890].

Gash, H., \& Domínguez, Rodríguez, P. (2009) Young people's heroes in France and Spain. Spanish Journal of Psychology , 12, 246-257.

Gotesky, R. 1952. The Nature of Myth and Society. American Anthropologist. 54. 523531. 
Hansen, W.F. 1998. Anthology of Ancient Greek Popular Literature. Bloomington: Indiana University Press.

Kieron O'Hara, Han Reichgelt, and Nigel Shadbolt. 1995. Avoiding Omnidoxasticity in Logics of Belief: A Reply to MacPherson. Notre Dame Journal Formal Logic. 36(3), pp. 475-495.

Jonas, H. 1963. Gnosticism, existentialism, and nihilism. In The Gnostic Religion. Beacon Press [1st edn. 1958]. Boston

Leeming, D.A. 1990. The World of Myth. New York: Oxford University Press.

Lévi-Strauss, Cl. 1974. The Structural Study of Myth. In Myth: A Symposium, ed. Thomas Sebeok. Bloomington: Indiana University Press, (originally published 1955): 81-106.

Maddy, P. 1990. Realism in Mathematics. Clarendon Press. Oxford.

Malinowski, B. 1992. Magic, Science and Religion and Other Essays. Prospect Heights, Ill: Waveland Press, Inc.

Nescolarde-Selva, J.,Vives-Macía, F., Usó-Domènech,J. L.,\& Berend, D. 2012ª An introduction to Alysidal Algebra (I). Kybernetes, 41(1/2), 21-34.

Nescolarde-Selva, J.,Vives-Macía, F.,Usó-Domènech, J. L.,\& Berend, D. 2012ํㅡ. An introduction to alysidal algebra (II). Kybernetes, 41(5/6), 780-793.

Nescolarde-Selva, J.and Usó-Doménech, J.L. 2012 . An introduction to Alysidal Algebra III. Kybernetes 41(10), 1638-1649.

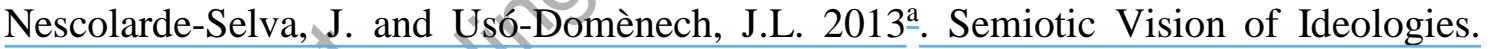
Foundations of Science. DOI 10.1007/s10699-013-9329-9.

Nescolarde-Selva, J and Usó-Doménech, J., L. 2013 ${ }^{\mathrm{b}}$. Reality, System and Impure Systems Foundations of Science. DOI: 10.1007/s10699-013-9337-8.

Nescolarde-Selva, J. and Usó-Doménech, J., L. 2013 . Topological Structures of Complex Belief Systems. Complexity. 19(1). pp. 46-62. DOI: 10.1002/cplx.21455.

Nescolarde-Selva, J. and Usó-Doménech, J., L. 2013 . Topological Structures of Complex Belief Systems (II): Textual Materialization. Complexity. 19(2). pp. 50-62. DOI. 10.1002/cplx.21476.

Pietroski, P. 1993. Possible worlds, syntax and opacity. Analysis.53. 270-280.

Platón. 1989. La República. Libro II. Socrates Adeimantus. Editorial Juventud. (In Spanish) 
Radin, P. 1950. The Basic Myth of the North American Indians. In EranosJahrbuch: Der Mensch und die Mythische Welt, Band XVII (1949).Winterthur, Switzerland: Rhein-Verlag Zurich, 359-419.

Rose, Ph. 2007. Philosophy, Myth, and the "Significance" of Speculative Thought. Metaphilosophy. 38(2). 632-653.

Shweder, R. A. (1977) Likeness and likelihood in everyday thought: Magical thinking in judgments about personality. Current Anthropology, Vol. 18, No.4, 637-658.

Segal, R.A. 2011. What is "Mythic Reality”?. Zygon: Journal of Religion and Science. Zygon: Journal of Religion and Science. 46(3). 588-592.

Tylor, E. B. 1871. Primitive Culture. 2 vols. London: Murray, 1st edn.

Usó-Domènech, J.L., Vives-Maciá, F., Nescolarde Selva, J. and Patten, B.C. 2009a . A Walford 's metadynamic point of view of ecosustainability ideology (I). INTERSYMP.

Usó-Domènech, J.L., Vives-Maciá, F., Nescolarde Selva, J. and Patten, B.C. 2009를 A Walford 's metadynamic point of view of ecosustainability ideology (II). INTERSYMP.

Usó-Doménech, Nescolarde-Selva, J. 2012.Mathematic and semiotic theory of ideological systems. Editorial LAP. Sarrebruck. Germany.

Weinreb, F. 1986. Roots of the Bible. Merlin Books Ltd. Great Britan.

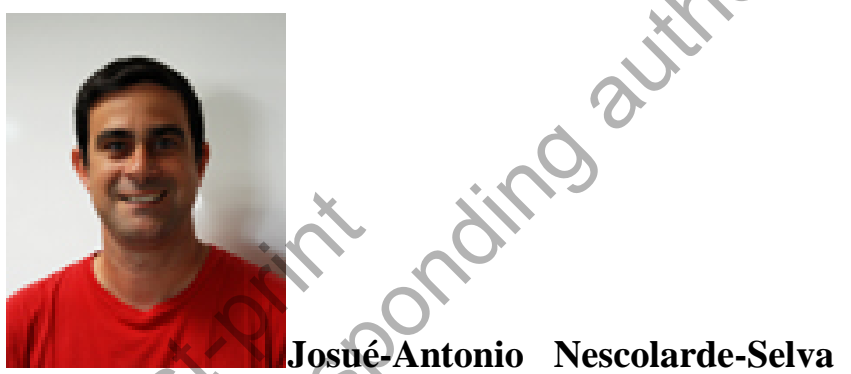

graduated in Mathematics from the University of Havana (Cuba) in 1999. He won the award: Gold Title at the University of Havana, Cuba in 1999. He received the PhD degree in Mathematics from the University of Alicante (Spain) in 2010. Since 2002, he has been working in the Department of Applied Mathematics, University of Alicante, Spain. He is author and co-author of several papers in journals and books. He is devoted to research on the Theory of Systems and Belief Systems.

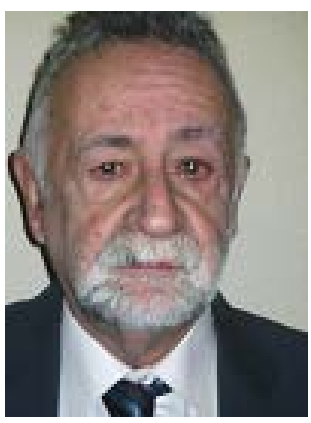


Josep-LLuis Usó-Doménech, is graduated in Sciences and Doctor in Mathematics by the University of Valencia(Spain). He made his doctoral thesis on a mathematical model of a terrestrial mediterranean ecosystem. He has directed many doctoral thesis in Theory of Systems. He is author and co-author of several papers in journals, proceedings and books. He has obtained scholarships of research in many universities (University of Joensuu, Finland; University of Ben Gurion of Negev, Israel and the University of Georgia, USA). He has collaborated in numerous occasions with the Wessex Institue of Tecnology(UK) and fruit of this collaboration was the creation of the international congress ECOSUD.

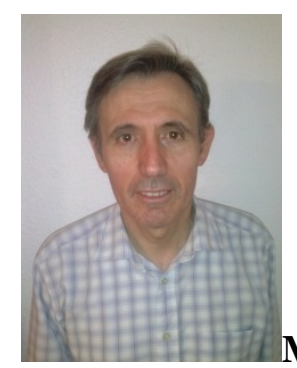

Miguel Lloret-Climent has a doctorate in Mathematics from the University of Alicante (Spain) and this currently professor of Applied Mathematics in the University of Alicante. He is author and co-author of several papers in journals and proceedings. He is devoted to general research on the Theory of General Systems and Biocybernetics. 